\title{
Ethmoid mucocele in a 5-year-old patient with- out cystic fibrosis
}

\author{
Wakisa Mulwafu, $M B C h B$ \\ Division of Otolaryngology, University of Cape Town \\ Gisella Furlan, MB BCh, FCRad (D) SA \\ Department of Radiology, Red Cross Children's Hospital and \\ University of Cape Town \\ Nico Jonas, MB ChB, FRCS (Glas), FCORL (SA) \\ Division of Otolaryngology, University of Cape Town
}

\section{Abstract}

Paranasal sinus mucoceles are extremely rare in children. We report a case of a 5-year-old boy with no evidence of cystic fibrosis who underwent endoscopic marsupilisation of an ethmoid mucocele.

\section{Case report}

A previously well 5 -year-old boy presented to our department with a 3-week history of a swollen, teary left eye. He did not have any systemic complaints, and no specific ear, nose or throat symptoms.

On examination he was apyrexial and appeared systemically well. Examination of his eyes revealed left-sided proptosis, but his visual acuity and eye movements were normal.

His oral cavity and oropharynx appeared normal and anterior rhinoscopy revealed no abnormality. Endoscopic nasal examination revealed a smooth-surfaced mass protruding from the upper part of the middle meatus on the left side. The rest of the examination was noncontributory.

Laboratory investigations including a full blood count and electrolytes were normal and he had a normal chest X-ray. A sweat test performed was negative for cystic fibrosis.

Computed tomography (CT) (Figs. 1 - 3) of his orbits and sinuses was performed and revealed a mixed-density soft-tissue expansile mass arising in the left ethmoid sinus, causing thinning and bowing of the medial wall of the left orbit. There was minimal rim enhancement of the mass. The mass caused minimal lateral displacement of the left optic nerve and mild left proptosis, but resulted in obstruction of the left maxillary antrum.

The patient underwent endoscopic marsupilisation of the mucocele. Biopsies of the cyst wall showed strips of mucoperiosteum with fragments of reactive bone. The mucosa was lined by respiratory epithelium with subepithelial chronic inflammatory cell infiltrate. There was no evidence of malignancy.

A repeat CT scan was done 4 weeks post surgery and showed no residual mass. At 6-month follow-up, endoscopic nasal examination showed no recurrence.

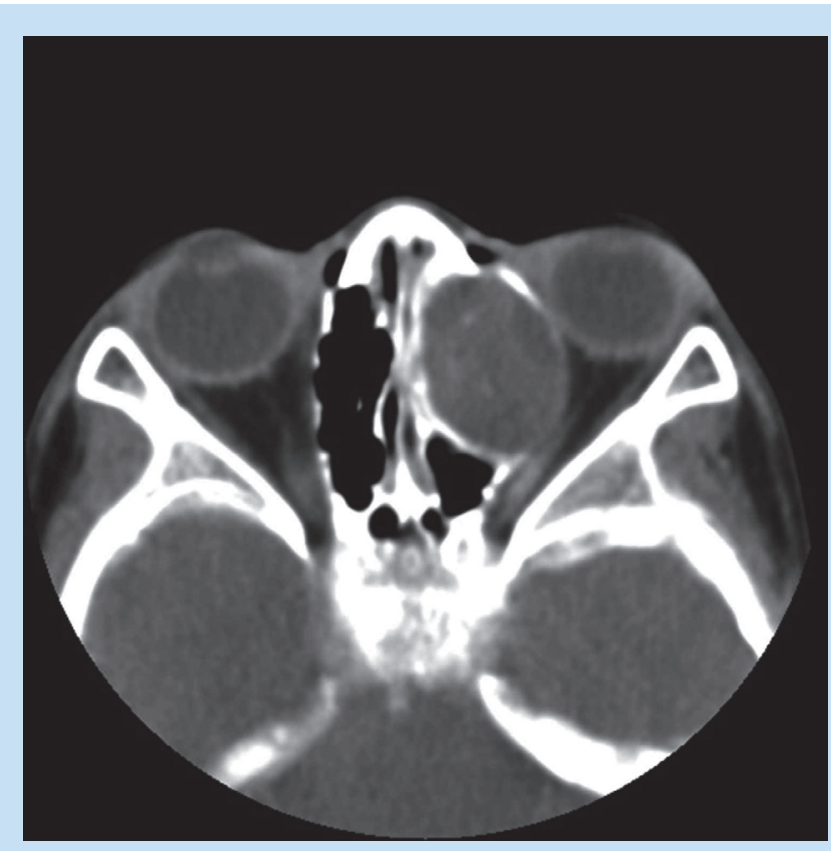

Fig. 1. Axial CT scan (soft-tissue window post contrast) shows a mixeddensity soft-tissue expansile mass arising in the left ethmoid sinus, causing thinning and bowing of the medial wall of the left orbit.

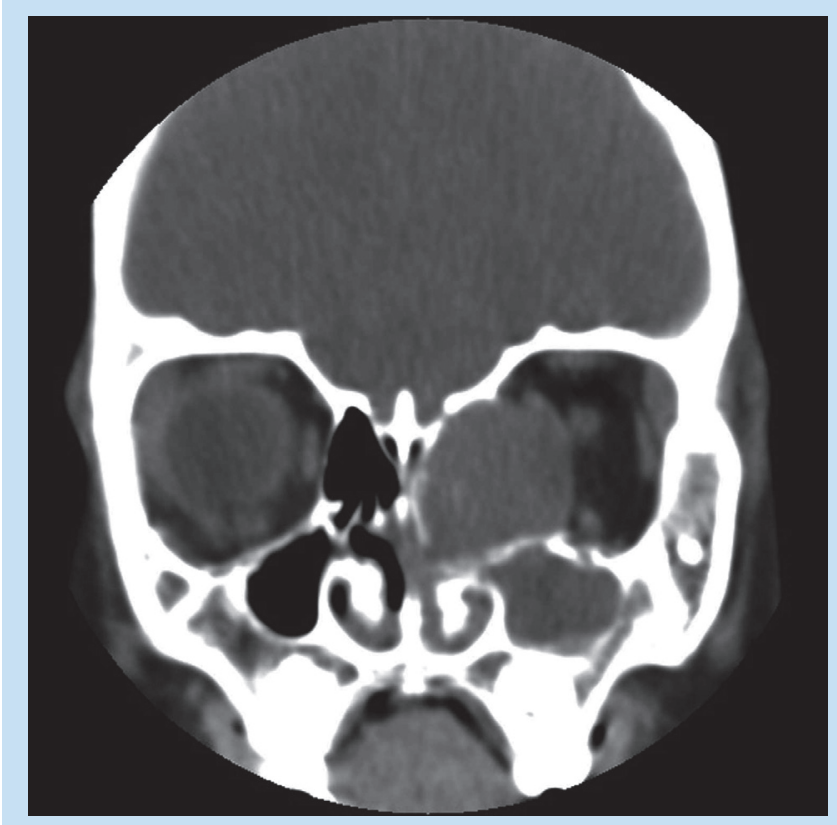

Fig. 2. Coronal CT scan (soft-tissue window) shows minimal rim enhancement of the left ethmoid mucocele, with no enhancement of its content - central high-density foci (within the mucocele) are due to inspissated mucus. There is minimal displacement of the left optic nerve and mild left proptosis. There is associated obstruction and opacification of the left maxillary antrum. 


\section{CASE REPORT}

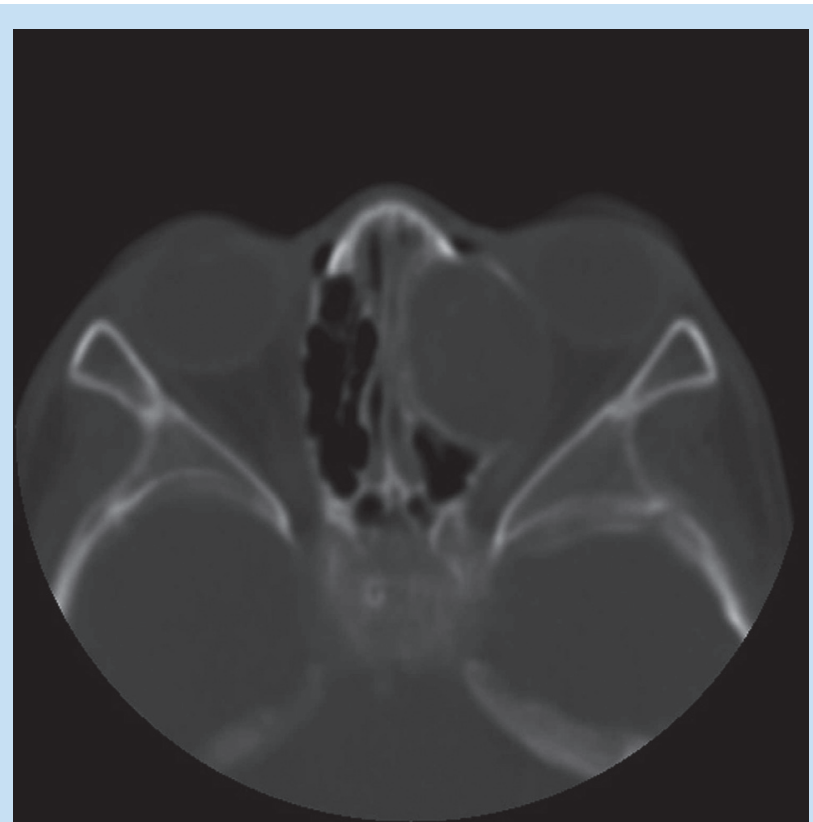

Fig. 3. Axial CT scan (bone window). There is evidence of thinning and remodelling of the walls of the expanded left ethmoid sinus. There is no evidence of bony destruction.

\section{Discussion}

A mucocele is an epithelial-lined mucus-containing sac that fills a paranasal sinus and is capable of expansion by bone resorption and new bone formation. ${ }^{1}$ They are extremely rare in children and their presence warrants thorough investigation to rule out aetiological entities such as cystic fibrosis. ${ }^{2}$ Paediatric mucoceles were previously thought to occur predominantly in patients with cystic fibrosis but some authors have recently reported mucoceles occurring in patients who do not have cystic fibrosis.,

Ethmoid sinus mucoceles often appear with painless orbital swellings. ${ }^{2}$ They may also produce frontal headaches and proptosis. ${ }^{2}$ Differential diagnoses of ethmoid sinus mucoceles in the paediatric population include meningocele, rhabdomyosarcoma, haemangioma, neuroblastoma and bony lesions such as fibrous dysplasia and osteomas. ${ }^{5}$
Mucoceles of the frontal sinus can often be diagnosed on plain X-ray films. Because of overlapping bone structures, mucoceles of the maxillary, sphenoid and ethmoid sinuses may not be apparent on X-ray. For this reason CT scan is the primary imaging method of choice. ${ }^{6}$

On CT, a mucocele appears as a non-enhancing, low-density expansile mass filling the sinus, with remodelling and/or thinning of the bony sinus walls. ${ }^{7}$ Mucoceles have variable densities on CT depending on protein content, inspissation and superinfection. ${ }^{8}$ Following intravenous contrast administration the lining of the mucocele may be enhanced. ${ }^{4}$ Magnetic resonance imaging (MRI) is only indicated if uncertainty persists following a CT scan. ${ }^{4}$ MRI can provide information about tissue composition, therefore enabling differentiation between different lesions which may be of similar density on CT. ${ }^{9}$

Mucoceles are managed surgically and most authors advocate marsupilisation rather than complete excision. ${ }^{4,10}$ Endoscopic management of paediatric ethmoid mucoceles is recommended as this enables exceptional visualisation of the surrounding anatomy and identification of vital structures which allows for a safe and minimally invasive treatment option. The endoscopic approach avoids an incision and subsequent facial scarring

In conclusion, ethmoid mucoceles in the paediatric population are rare but can occur in the absence of cystic fibrosis. CT scan is the primary imaging method of choice and endoscopic marsupilisation is recommended.

1. Lund VJ, Milroy CM. Fronto-ethmoidal mucoceles: a histopathological analysis. J Laryngol Otol 1991; 105: 921-923.

2. Alvarez RJ, Liu NJ, Isaacson G. Pediatric ethmoid mucoceles in cystic fibrosis: long term follow-up of reported cases. Ear Nose Throat J 1997; 76: 538-539, 543-546.

3. Zrada SE, Isaacson GC. Endoscopic treatment of pediatric paranasal ethmoid mucoceles. Am J Otolaryngol 1996; 17: 197-201.

4. Hartley BE, Lund VJ. Endoscopic drainage of pediatric paranasal sinus mucoceles. Int J Pediatr Otorhinolaryongol 1999; 50: 109-111.

5. Nicollas R, Facon F, Sudre-Levillain I, Forman C, Roman S, Triglia JM. Pediatric paranasal sinus mucoceles: etiologic factors, management and outcome. Int J Pediatr Otorhinolaryngol 2006; 70: 905-908.

6. Lloyd G, Lund VJ, Savy L, Howard D. Optimum imaging for mucoceles. J Laryngol Otol 2000; 114: 233236

7. Harnsberger HR, Wiggins RH, Hudgins PA, et al. Mucocele, sinonasal. In: Diagnostic Imaging: Head and Neck. Salt Lake City: Amirsys 2004, 56-58

8. Kosling S, Hintner M, Brandt S, Schulz T, Blonching M. Mucoceles of the sphenoid sinus. Eur J Radiol 2004; 51: 1-5.

9. Ishibashi T, Kikuchi S. Mucocele-like lesions of the sphenoid sinus with hypointense foci of T2-weighted magnetic resonance imaging. Neuroradiology 2001; 43: 1108-1111.

10. Sciarretta V, Pasquini E, Farneti G, Ceroni AR. Endoscopic treatment of paranasal sinus mucoceles in children. Int J Pediatr Otorhinolaryngol 2004; 68: 955-960. 